This is a pre-publication (i.e. submission) version of a paper that has been published online at Theory and Society: https://doi.org/10.1007/s11186-020-09407-z. It is different from the final published version only in minor ways. If you cite this paper, please use the official published version.

\title{
Making Platforms Work: Relationship Labor and the Management of Publics
}

\author{
Benjamin Shestakofsky \\ University of Pennsylvania \\ Shreeharsh Kelkar \\ University of California, Berkeley*
}

\begin{abstract}
How do digital platforms govern their users? Existing studies, with their focus on impersonal and procedural modes of governance, have largely neglected to examine the human labor through which platform companies attempt to elicit the consent of their users. This study describes the relationship labor that is systematically excised from many platforms' accounts of what they do and missing from much of the scholarship on platform governance. Relationship labor is carried out by agents of platform companies who engage in interpersonal communications with a platform's users in an effort to align diverse users' activities and preferences with the company's interests. The authors draw on ethnographic research conducted at AllDone (a for-profit startup that built an online market for local services) and edX (a non-profit startup that partnered with institutions to offer Massive Open Online Courses). The findings leverage variation in organizational contexts to elaborate the common practices and divergent strategies of relationship labor deployed by each platform. Both platforms relied on relationship workers to engage in account management practices aimed at addressing the particular concerns of individual users through interpersonal communications. Relationship workers in each setting also engaged in community management practices that facilitated contact and collaboration among users in pursuit of shared goals. However, our findings show that the relative frequency of relationship workers' use of account management and community management practices varies with organizational conditions. This difference in strategies also corresponded to different ways of valuing relationship workers and incorporating them into organizational processes. The article demonstrates how variation in organizational context accounts for divergent strategies for governing user participation in digital platforms, and for the particular processes through which governance is accomplished and contested.
\end{abstract}

*The authors are listed in reverse alphabetical order. Both authors contributed equally to the manuscript. The authors thank Sharon Zukin, Karolina Mikołajewska-Zając, Tom Gilbert, Devika Narayan, anonymous reviewers, and participants in UC Berkeley's Algorithmic Fairness and Opacity Working Group (AFOG) for their feedback on this article. Jerry Jacobs, Sigrid Luhr, and Jonah Stuart Brundage directed us to helpful references. 
Digital platforms bring into existence—and exert control over—communities of users. At the same time, however, platforms are dependent upon and accountable to the publics that they serve. Given the tensions that arise as platform companies attempt to balance their own interests with the competing interests of users, the question of "platform governance"--how platforms control users' activities and structure the terms of participation--has figured prominently in contemporary research (Fish et al. 2011; Bucher 2013; Gillespie 2014; Rosenblat and Stark 2016; Gorwa 2019; Suzor 2019). ${ }^{1}$

Existing studies elaborate how platform companies govern by establishing rules of participation, and how they enforce their policies by deploying technological tools (CheneyLippold 2011; Helmond 2015; Rosenblat and Stark 2016), corporate rhetoric (Gillespie 2010; Dror 2015; Rosenblat and Stark 2016), and human moderators (Gillespie 2018a; Roberts 2019). In this study, we focus instead on relationship labor, which is complementary to these efforts but often systematically excised from platforms' accounts of what they do.

Relationship labor is carried out by agents of platform companies who engage in interpersonal communications with a platform's users in an effort to align diverse users' activities and preferences with the company's interests. Relationship labor is a subset of articulation work--practices that support "the smooth interaction of parts within complex sociotechnical wholes, adjusting and calibrating each to each" (Jackson 2014:223). We argue that relationship labor constitutes an underspecified mechanism through which companies secure users' long-term attachment to digital platforms.

\footnotetext{
${ }^{1}$ Some scholars use the term "platform governance" to refer to the governance of platform companies by users, governments, laws, and regulations. Here we are primarily concerned with the governance of users by platforms (Gorwa 2019).
} 
Relationship labor refers to an amalgamation of activities that have previously been documented in other work settings but are combined in new ways on digital platforms. For example, like corporate call-center agents and sales representatives, relationship workers are often tasked with increasing customer loyalty by managing customers' emotional states and providing personalized assistance (Hochschild 1983; Dyché 2001). Like independent musicians (Baym 2015) and social media "influencers" (Duffy 2017), relationship workers may use affective labor to cultivate long-term ties with members of online communities. And like administrators of open-source software (Coleman 2013), relationship workers may also foster partnerships between individual stakeholders whose collective efforts generate value for the enterprise in which they participate. The unique characteristics of digital platforms can afford many forms of participation (Fish et al. 2011) while distributing control among participants (Vallas and Schor forthcoming). Platform companies employ relationship workers to speak to multiple groups in multiple registers in order to manage the frictions that emerge between and among platform companies and their users.

To describe relationship labor, this study compares the organizational practices of two different platform companies at which the authors conducted ethnographic research. AllDone is a Silicon Valley-based startup that built a digital platform for buyers and sellers of local services. ${ }^{2}$ edX is a startup headquartered in Cambridge, Massachusetts that partners with institutions to offer Massive Open Online Courses (MOOCs). The two cases were selected to exploit similarities across organizational logics and stages of development, as well as variation in multiple dimensions of organizational context.

\footnotetext{
${ }^{2}$ The names of the company and associated individuals have been changed.
} 
Our findings outline the common types of relationship labor and divergent strategies for platform governance that each platform deployed. Both platforms relied on relationship workers to engage in account management practices aimed at addressing the particular concerns of individual users through interpersonal communications. Relationship workers in each setting also engaged in community management practices that facilitated contact and collaboration among users in pursuit of shared goals. However, the relative frequency of relationship workers' use of these practices varied with organizational conditions, with edX implementing a far more comprehensive set of community management techniques than AllDone. This variation in strategy also corresponded to different ways of valuing relationship workers and incorporating them into organizational processes: whereas AllDone's relationship labor was offshored, lowpaid, and largely invisible to its technical workforce, edX's relationship workers received more generous compensation and worked side-by-side with the company's software engineers.

In the following section, we survey prior research on platforms and platform governance. We argue that studies of rules and technologies often obscure additional social processes and interpersonal interactions through which platform companies secure the consent of their users. We then introduce our research sites and the logic of our comparison. Next, we present the practices through which each platform sought to manage relationships with its users. Finally, we leverage the variation in the organizational contexts of our two sites to show how platforms may pursue divergent strategies to govern user participation. We conclude by discussing the implications of our findings for theories of platform governance, the connection between algorithmic systems and human labor, and gender segregation in the tech industry. 


\section{Platform Governance}

Digital platforms "provide a set of shared techniques, technologies, and interfaces to a broad set of users who can build what they want on a stable substrate" (Kenney and Zysman 2016:62). Beginning in the 1980s, firms like Microsoft and Intel began to use the term "platform" to describe their business models. Rather than pursuing complete vertical integration, these firms created systems upon which external developers, or "complementors," could build new products (Gawer and Cusumano 2002; Plantin et al. 2018). The advent of Web 2.0 added a new dimension to how the term "platform" was used. While the complementors of the 1980s and '90s were typically software developers, social media companies like Facebook and YouTube deployed the term to describe their relationships with myriad content producers, consumers, and advertisers. All of these groups became "users" of the platform. ${ }^{3}$

There exists a symbiotic relationship between platforms and their varied users. For example, the popularity of Microsoft Windows depended on the quality and quantity of software created for Windows by its users (i.e. external developers); at the same time, software developers were more eager to write programs for Windows when they knew there were more computers running the operating system (Gawer and Cusumano 2002). On a discursive level, platform companies emphasize the mutual dependence between platforms and users by framing their services as "flat and neutral spaces open to all comers" (Gillespie 2010:358).

In reality, however, platforms are also sites of tension. Conflicts over the terms of participation often emerge between platform companies and their users (Gillespie 2010; Fish et al. 2011). Platform companies make policy and design decisions to advance their own interests,

\footnotetext{
${ }^{3}$ In the software industry, the term "user" is typically applied to a broad range of parties who may engage with the same platform in different ways (Agre 1995; McKay et al. 2000; Eisenmann, Parker, and Van Alstyne 2009). For example, ordinary people, organizations, and advertisers can all be "users" of social media platforms like Facebook; both passengers and drivers are "users" of ride-hailing platforms like Uber; and restaurants, drivers, and diners are all "users" of food-delivery platforms like Grubhub.
} 
sometimes at the expense of their users. For example, Uber claims that its algorithms simply reflect market forces, but in fact Uber's software engineers design their algorithms to manipulate supply and demand so as to maximize profits at the expense of drivers (Rosenblat 2018). Senior Wikipedia editors have developed bureaucratic procedures to prevent vandalism, but in doing so have made it more difficult for new editors to contribute (Geiger 2017). And when Flickr was acquired by Yahoo, professional photographers who used the site chafed at the company's new user agreement, which granted Yahoo the right to sell or display any user's work (Van Dijck 2013).

Platform companies must also attempt to balance the competing interests of users. For instance, some Facebook users may perceive an image of a mother breastfeeding as obscene; to others, removing such photos from the site sends a troubling message that, as one user put it, breastfeeding "is something shameful, something that should be hidden and not seen" (Gillespie 2018a:154). In short, the openness of digital platforms can generate contradictory effects: to produce value, platforms must attract users and empower them to participate by creating or consuming content or services; however, users' preferences and voices can run counter to each other's interests or to the interests of platform companies themselves.

The rise of digital platforms has thus brought renewed attention to how companies govern their platforms to address the problem of managing relationships with their multifarious users. The threat faced by platform companies is twofold. If users feel that their interests are not being served by the platform, they may exit, perhaps migrating to a competitor. Alternatively, aggrieved users may stay, but inflict lasting reputational damage such that new users are repelled. Both scenarios are dangerous to platform companies whose fortunes hinge on attracting 
an ever-greater number of users to maximize network effects and profits (Kenney and Zysman 2016; Parker, Van Alstyne, and Choudary 2016; Srnicek 2017).

From Rules and Technologies of Governance to Relationship Labor

Researchers who examine how platforms govern users are largely concerned with questions of what is allowed and who is responsible (Van Dijck 2013; Gillespie 2018a; Gorwa 2019; Suzor 2019): What types of participation are permitted on the platform? What are the conditions of participation? Who is accountable for the activities of users? Who is accountable for how platforms affect politics, cultures, and societies? All of these questions are concerned with "the political implications of the algorithmic systems deployed by platform companies" (Gorwa 2019:5; see also Bucher 2018). This perspective on governance emphasizes the role of technological systems and human discretion in determining how the rules of participation are set, implemented, and enforced. This article, however, takes a different approach, focusing instead on the activities of the workers that platforms employ to aid and persuade users through interpersonal communication. We call this work relationship labor, and we argue that this perspective brings to light governance processes that prior research on policies and technologies tends to occlude.

The question of "what is allowed" on platforms has dominated newspaper headlines in recent years. Platforms with massive user populations like Facebook and YouTube rely on thousands of far-flung workers to quickly review user-generated content on an industrial scale. "Commercial content moderators" screen out materials that violate a platform's guidelines by removing text, photos, and videos that are violent, sexually explicit, or otherwise disturbing or inappropriate (Klonick 2017; Gillespie 2018a; Roberts 2019). Content moderation is 
simultaneously aimed at protecting users from each other, and at preserving the platform's value to advertisers and its reputation among the broader public. However, the industrial-scale policing of user activity has generated an unending series of controversies pertaining to both platform companies' shifting rules and rationales, and content moderators' uneven enforcement of everchanging policies (Gillespie 2018a).

The question of "who is responsible" is, if anything, even more vexing. The difficulty here stems from the fact that platforms use complex technological systems, including algorithms and digital interfaces, to invite participation from users and shape their activities (Gillespie 2014; Helmond 2015; O’Neil 2016; Rosenblat and Stark 2016; Ask et al. 2019). Platforms use algorithms to sort, rank, categorize, and display users and content in order to invite particular kinds of participation from stakeholders (Cheney-Lippold 2011; Fourcade and Healy 2017). The use of algorithms and interfaces delimits the terms of participation by allowing users to perform certain types of activities while foreclosing other possibilities, reflecting and reproducing power asymmetries between platform companies and users (Tufekci 2014; Rosenblat and Stark 2016). Given how platform technologies structure user activities, it can be difficult to disentangle where the responsibility of the platform company ends, and where the user's responsibility begins.

While researchers of platform governance have opened the "black box" of algorithmic opacity to reveal the political implications of platform policies and design, they have tended to focus on the impersonal and procedural aspects of how platform companies govern their users. Gillespie (2018b) argues that when social media platforms deploy content moderators to police user behavior, they "must work at an impersonal scale: the scale of data. [...] This is not customer service or community management but logistics—where concerns must be addressed not individually, but procedurally." As a result, social media users often end up "feeling like a data 
point." Similarly, Uber drivers who experience problems with the platform quickly discover that the company's customer support system is largely automated; drivers are without recourse to a company representative who "understands and is responsive to nuances" (Rosenblat 2018:143). Although providing customer support at "the scale of data" may be sufficient for handling routine queries, it generates frustration and distrust in the system among drivers. Impersonal socio-technical systems are unable to adequately explain how a platform's rules were applied to a user's particular circumstances, nor to justify or adjust the platform's treatment of the user in light of his or her specific grievances. How do platform companies address the dissatisfaction and concern that are systematically generated by their products?

Shifting our perspective from policies and technologies to relationships can reveal important new insights into how platform companies manage users. In this article, we advance a more expansive view of the politics of platforms--one that accounts not only for the definition and enforcement of rules, but also for "the group of multilateral negotiations, trials of strength and tricks" through which platform companies attempt to persuade users and stabilize the meaning of a situation in their own terms (Callon 1984:211). Following political theorists, we view governance as encompassing not only the procedures codified in regulations, but also "the means used to shape or change the behaviour of people in order to achieve [the] goals" prescribed by rules and regulations (Bell, Hindmoor, and Mols 2010:852). These may include persuasive appeals to self-interest or social obligation. By drawing attention to the "tasks that have to be performed to sustain the routinized arrangements of the prevailing order" (Rosenau 2009:6), we demonstrate the crucial role of governance processes involving interpersonal 
communications in maintaining the perceived legitimacy of a platform and securing the ongoing consent and commitment of its users. ${ }^{4}$

Some studies have touched on the persuasive dimensions of platform governance by noting how platform companies craft narratives aimed at convincing users and publics that the platform serves the common good rather than the narrow interests of any one party (Gillespie 2010). Platform companies attempt to defuse tensions by framing themselves as neutral--rather than self-interested--intermediaries (Gillespie 2010; Kenney and Zysman 2016; Rosenblat 2018), or by claiming that their company's mission is not the pursuit of profits or prestige, but instead "to make the world a better place" (Shapin 2008; Dror 2015). However, the explanatory power of this perspective remains limited. Although it highlights how technological systems are intertwined with companies' "linguistic strategies of argumentation" (Dror 2015:543), it has less to say about users' reception of and responses to company rhetoric and how the platform-user relationship is maintained on a day-to-day basis.

We introduce the concept of relationship labor to describe the work of paid employees-with job titles that include customer support agent, community manager, and program manager-who engage in interpersonal communications with users in an effort to sustain user engagement with the platform. ${ }^{5}$ Some research on platform governance has touched on elements of

\footnotetext{
${ }^{4}$ Platform scholars who share this broader view of governance (e.g. Fish et al. 2011; Kelty et al. 2015) have neither identified nor discussed relationship labor, perhaps because they have primarily endeavored to build general theories and typologies of participation rather than systematically investigating how governance processes are implemented within concrete social settings.

${ }^{5}$ We distinguish relationship labor from two associated, but distinctly different, terms. Like "relational work" (Zelizer 2005; Bandelj 2012, 2015), relationship labor draws attention to how economic transactions are imbricated in social relations. But rather than focusing on "the effort by which people try to find appropriate matches between social relations, economic transactions, and media of exchange" (Bandelj 2015:227-228), relationship labor is concerned with how employees aid and persuade platform users. Like "relational labor" (Baym 2015:16), relationship labor "is meant to emphasize effort that goes beyond managing others' feelings in single encounters...to creating and maintaining ongoing connections." However, unlike the relational labor exhibited by musicians as they cultivate audiences to
} 
relationship labor. Volunteer moderators tasked with enforcing the rules of participation in smaller-scale online communities (e.g. Facebook Groups, Reddit subreddits, Twitch channels, and open-source projects) may not only enforce a group's policies, but also communicate directly with users to publicize their actions, explain the rules of participation, and defend the perceived interests of the community (Seering et al. 2019). ${ }^{6}$ Volunteer moderation is a social process that, although motivated by enforcement activities, can simultaneously contribute to the engagement of users and the development of community. The governance of small-scale, online groups can be figured as an ongoing, interactive accomplishment, whereby platform companies' technological design, combined with "bottom-up" enforcement actions, can elicit individualized and collective user responses, to which volunteer moderators themselves respond in an ongoing dialectic (Matias 2016; Squirrell 2019). The efforts of volunteer moderators can thus be calibrated "in a way that disciplines users without alienating them" (Squirrell 2019:1923).

However, interactions between paid agents of large-scale platforms and their users have yet to receive sufficient attention. Indeed, in contrast with small online communities united around a common interest, large-scale platforms are likely to include a greater and more heterogeneous set of users holding a wider variety of views and engaging in a broader array of activities. Additionally, platforms tend to subject users to frequent changes in technologies and policies that can spark user frustration (Shestakofsky 2017; Kelkar 2018; Nieborg and Poell

enhance their income-earning potential, relationship labor is wage-labor that does not require workers to blur the boundaries between professional and personal ties, and the value generated by relationship workers is appropriated by the companies that employ them. Additionally, relationship workers cultivate online communities not only to build customer loyalty, but also to encourage community members to collaborate in ways that will serve the interests of the platform company.

${ }^{6}$ Others have commented on the uses and misuses of the term "community" to describe those who participate in digital platforms (Postill 2008; Fish et al. 2011). Tech companies often deploy the word in ways that elide differences in power, interests, and opinions among and between platform companies and users. (Note, for example, the multiple uses of the term "community" in Zuckerberg 2017). Like other critics, our use of the term acknowledges that inequalities exist even among members of self-described online "communities." 
2018; Rosenblat 2018). In light of these conditions, further research is necessary to explain how platforms mobilize paid workers not only to enforce platform policies, but also to respond to user dissatisfaction and keep users engaged while simultaneously maintaining their prerogative to govern. $^{7}$

\section{Research Methods}

This study employs a novel methodological approach to investigating platform governance. $\mathrm{Li}$ (2007) argues that governance is best examined ethnographically by observing the actual practices through which governing strategies are pursued. By focusing on practices, analysts avoid portraying governing rationalities as total and absolute, and can instead focus on how people use existing resources to put governing strategies into action, the slippages that occur between what is planned and what actually happens, and how all of these day-to-day realities can cement governance strategies while still leaving room for change. To our knowledge, this study is among the first (see also Seaver 2019) to document the internal organization of platform companies by drawing on direct observations of how they conceptualize and execute the task of keeping users engaged with the platform. ${ }^{8}$

\footnotetext{
${ }^{7}$ Relationship labor can be glimpsed in emerging studies of digital labor platforms. Some freelancing platforms employ workers who post to online discussion boards frequented by users to provide advice or forecast upcoming changes to the software (Rahman 2019; Gerber and Krzywdzinski 2019). On one ondemand delivery platform, managers call couriers to enforce scheduling policies (Attwood-Charles 2019). However, researchers have yet to systematically investigate how platform companies organize relationship labor, nor the interactional practices and strategies that they use to manage their user populations.

${ }^{8}$ Prior studies employ content analyses of the rhetoric deployed by platform companies (Gillespie 2010) and of users' social media posts pertaining to governance disputes (Crawford and Gillespie 2016); examinations of user interfaces and their implications for platforms' control over user activities (Helmond 2015; Rosenblat and Stark 2016); and observations and interviews that surface users' and managers' opinions and experiences of platform governance (Bucher 2013; Rosenblat and Stark 2016; Gerber and Krzywdzinski 2019).
} 
To understand how platform companies manage users, we draw on the "matched pair approach" to comparative ethnographic analysis, according to which cases are selected based on shared parameters that are constant across different settings (Bechky and O'Mahony 2015). Each of the authors had independently conducted ethnographic studies of early-stage digital platforms in the process of scaling up their operations, and each had found that the platform employed workers tasked with managing users' experiences and expectations (see identifying references). After noticing the parallels between our research settings, we re-examined our ethnographic data to generate a more nuanced account of the particular strategies and practices through which each platform managed its users. Examining divergent settings bolsters the analytic power of our case studies by increasing the likelihood that theory generated from this analysis will be robust (Bechky and O’Mahony 2015).

The two companies we analyze shared a mission of using technology to "disrupt" traditional modes of service provision, but varied in their business models and goals, distinctions that are likely to animate substantial variance in the practices of platform governance (Van Dijck 2013; Kelty et al. 2015). AllDone was a for-profit, venture capital-backed platform that aimed to connect buyers and sellers of local services. Its ultimate goal was to rapidly multiply the company's valuation, resulting in exponential returns for owners of equity in the firm via a lucrative corporate acquisition or initial public stock offering. edX was a non-profit platform that collaborated with institutions to offer Massive Open Online Courses. edX received initial seed funding from Harvard and MIT, and thereafter derived operating revenue from fees paid by institutions to have edX host their courses, as well as fees paid by learners who wished to earn a certificate. edX was committed to pursuing the project of educational reform while also endeavoring to secure its own financial sustainability. 


\begin{tabular}{|c|c|c|}
\hline $\begin{array}{l}\text { Field Setting } \\
\text { Dimensions }\end{array}$ & edX & AllDone \\
\hline Commonalities & & \\
\hline $\begin{array}{l}\text { Organizational } \\
\text { logic }\end{array}$ & $\begin{array}{l}\text { Achieve goals through rapid } \\
\text { growth }\end{array}$ & $\begin{array}{l}\text { Achieve goals through rapid } \\
\text { growth }\end{array}$ \\
\hline $\begin{array}{l}\text { Temporal trajectory } \\
\text { of platform at time } \\
\text { of research }\end{array}$ & $\begin{array}{l}\text { Early-stage organization (one year } \\
\text { after launch) }\end{array}$ & $\begin{array}{l}\text { Early-stage organization (two years } \\
\text { after launch) }\end{array}$ \\
\hline Differences & & \\
\hline Funding model & $\begin{array}{l}\text { University-funded, non-profit } \\
\text { enterprise }\end{array}$ & $\begin{array}{l}\text { Venture-funded, for-profit } \\
\text { enterprise }\end{array}$ \\
\hline Relative resources & More funding; more employees & Less funding; fewer employees \\
\hline Types of "users" & $\begin{array}{l}\text { Individuals (learners, instructors, } \\
\text { researchers) and institutions } \\
\text { (universities, corporations) }\end{array}$ & $\begin{array}{l}\text { Individuals (buyers and sellers of } \\
\text { local services) }\end{array}$ \\
\hline Goal & Prestige for stakeholders & Profit for shareholders \\
\hline
\end{tabular}

Table 1: Similarities and differences between the two settings

We have identified two key similarities and four important differences between the two platform companies (Table 1). In the remainder of this section, we describe the two platform companies, the nature of our fieldwork in each, and their similarities and differences. 
AllDone was a Silicon Valley-based startup that built a digital platform for buyers and sellers of local services. AllDone's offerings covered hundreds of service categories, such as house cleaning, wedding photography, tutoring, and plumbing. Buyers who visited AllDone's website or app could enter a request for a local service provider to perform a job for them. Buyer requests were then distributed to AllDone's network of nearby sellers, who could choose to pay AllDone a small fee to pitch their services to buyers.

For the majority of the first author's fieldwork, AllDone's staff in San Francisco totaled 20 employees divided into engineering, design, marketing, business, and operations divisions. AllDone maintained a team of 200 work-from-home contractors in the Philippines who performed routine information-processing tasks to support or stand in for the company's algorithmic systems. The company also employed 10 work-from-home team members in the Las Vegas area to provide telephone-based customer support to users.

The first author conducted 19 months of participant-observation research at AllDone's office in San Francisco between 2012-2013. He began working for AllDone as an unpaid intern while simultaneously recording fieldnotes and gathering data about the company's operations. He soon transitioned into a part-time, paid role as a marketing analyst and then worked full-time for 12 months as AllDone's director of customer support and operations manager while continuing to conduct research. ${ }^{9}$ In these roles, the first author collaborated closely with

\footnotetext{
${ }^{9}$ The first author gained access to the field site through a friend who had attended high school with one of AllDone's co-founders. The first author told the co-founder that he was interested in studying everyday life inside a tech startup by working alongside members of the organization. Upon being granted access, he informed colleagues of his dual role as both a researcher and participant. The first author engaged in a variety of mental activities--including reviewing and analyzing each day's fieldnotes--to maintain a degree of "professional distance" essential to generating insights from data (Anteby 2013). Although he was deeply involved in the field site, the first author did not generate the phenomena described in this article: the company's account management procedures were already in place when the first author began
} 
members of each of AllDone's three work teams, and traveled frequently to visit team members in the Philippines and Las Vegas.

$e d X$

edX was a start-up in Cambridge, Massachusetts that partnered with institutions to offer Massive Open Online Courses (MOOCs) that include text, videos, and machine-graded assessments. edX's model of course production hinged on a clear separation between software and pedagogy. edX made the software, which was then hosted on its website and used by instructors at partner institutions to build courses and conduct research on teaching and learning.

There were two broad classifications of workers at edX. The edX engineering team wrote the software that ran the edX portal; this software was used by educators at partner institutions to build courses and by learners to learn. The services team, on the other hand, coordinated with instructional teams and research teams at partner institutions to help them run their courses and determine best practices for teaching and learning.

The second author conducted a two-year ethnographic study of edX and four of its partner institutions (MIT, Harvard, UC Berkeley, and Stanford) between 2013 and 2015. At each institution, his sampling strategy was to interact with individuals representing as many organizational roles as possible so that he could understand the full range of work that was carried out to create educational experiences and knowledge about education. He spent time with various actors across the burgeoning edX ecosystem, including engineers and program managers at edX, as well as the instructors, researchers, video producers, instructional designers,

to work with AllDone's phone support agents, and its community management activities were implemented by a colleague working in a different department. See Appendix B of identifying reference for further details pertaining to the author's data-gathering procedures and analytic strategy. 
technologists, and other support staff working with edX's partners. He attended meetings (e.g. course team meetings, project status meetings), conducted interviews and informal conversations, witnessed many public and semi-public events, attended conferences and summer schools, and collected and reviewed a large number of circulating documents. ${ }^{10}$

\section{Commonalities}

In addition to being platforms, AllDone and edX shared two key similarities. First, both companies were committed to a logic of scale. The term "scale" describes how platform companies strive to develop infrastructure that will facilitate exponential user growth without commensurate growth in the labor or infrastructure required to run the platform, such that the marginal cost of serving each additional user will ideally be negligible (Parker et al. 2016). Like platforms such as Facebook and YouTube, managers at edX and AllDone believed that their products' potential could best be realized by accumulating as many users as possible.

In AllDone's case, this meant enrolling buyers and sellers on the platform and making sure that the software would be able to connect them. This would accomplish two objectives for AllDone. First, achieving scale would make the website more attractive to users because it would provide buyers with access to more choices when hiring local service providers, while simultaneously providing sellers with greater access to potential customers. Second, growing the user base would help the firm increase its revenue and market share, thereby increasing AllDone's legitimacy in the eyes of potential investors. edX had similar goals: increasing the number of courses on edX would increase the number of learners who were interested in

\footnotetext{
${ }^{10}$ Because the second author's role in the field involved a lesser degree of participation than the first author's, his access to managers' deliberations about platform strategy was more limited. However, the breadth of the second author's access (both inside of edX and among various users of the platform across four institutions) provided ample opportunities to observe the company's governance practices.
} 
enrolling in, and paying for, some of these courses, thereby ensuring edX's sustainability as a non-profit enterprise. But edX also aimed to recruit a large number of partners to use the platform to realize diverse modes of pedagogy in terms of style, content, and underlying theories of learning.

Second, at the time the authors conducted their ethnographic fieldwork, each of the companies was in a similar stage of its developmental trajectory. The second author's research began when edX was about one year old. It had received significant startup funding from Harvard and MIT and had just embarked on its project of scaling. By the time the second author finished his fieldwork, the number of edX's partners had increased from three to 91, and the number of courses had grown from 7 to 650 . AllDone was at a similar position when the first author began his participant-observation research: it had secured its first round of venture capital funding and received roughly 13,000 buyer requests per month. By the time he completed his fieldwork, the number of monthly buyer requests had increased to over 100,000, and AllDone had secured a second round of venture funding.

\section{Differences}

AllDone and edX differed along four important dimensions. First, edX was a non-profit organization and AllDone was a for-profit company. From a financial perspective, edX aimed to build and implement a business model that would make the company self-sustaining and no longer reliant on injections of funding from its founding institutions. AllDone was funded by venture capital investors seeking exponential returns on their initial investment in the company (Mason 2009). 
Second, because edX had considerably more initial funding than AllDone (\$60 million in seed funding vs. $\$ 4.5$ million in venture capital funding), its architects had a comparatively greater set of financial and human resources at their disposal. By the end of the second author's fieldwork, edX had about 100 employees, while at the end of the first author's fieldwork AllDone had 20 employees in the San Francisco office (though the company employed a large number of low-cost, distributed contractors in the Philippines and Las Vegas).

Third, each platform catered to different types of users. As an entrant in the "on-demand" service economy, AllDone's users were individuals interested in either hiring a service provider or providing a service. edX partnered with universities and corporations to offer Massive Open Online Courses (MOOCs) to anyone with an internet connection. Its clients were institutions such as universities, foundations, and for-profit corporations. Each client employed instructors and researchers who built courses and produced knowledge about online education. Learners used edX to take these courses (sometimes for free, other times for a fee).

Lastly, the architects of both AllDone and edX conceived of their products as platforms that would enable them to manage a diverse array of users. However, just as important to edX as market share was the company's prestige. edX's goal was to "reinvent education," and while attracting as many learners as possible was key to its financial sustainability, its patrons also saw the platform as a catalyst for inventing new methods of teaching and learning. Success would thus position the founding institutions, Harvard and MIT, as pioneers in educational innovation (Gebre-Medhin 2018). AllDone's patrons had no such expectations; the venture would stand or fall based on whether it could attract buyers and sellers, generate adequate revenue streams, and multiply the value of the firm so that stakeholders could achieve a massively profitable "exit" via corporate acquisition or IPO. 


\section{Analytic Approach}

We examine two platforms that shared a core process, yet differed in important ways in their contexts and outcomes. Both were early-stage companies that sought to acquire as many users as possible. Both platforms thus confronted the problem of achieving governance at scale (Gillespie 2018a): the more users each platform took on, the more possibilities emerged for tension and conflict to arise. We use variation in the companies' circumstances and structure to theorize how organizational context matters for the practices and strategies platforms use to address problems of governance. To the extent that the two platforms share tactics and strategies, this suggests their broad applicability; variation, on the other hand, can likely be traced to differences in organizational conditions.

\section{Making Platforms Work}

We now turn to our examination of the relationship labor deployed by AllDone and edX. Both platforms' relationship workers engaged in practices of account management aimed at addressing users' particular problems and concerns, as well as practices of community management designed to bring users together to collaborate with one another. However, the frequency of these practices varied across the two platforms: while AllDone only experimented with community management practices, community management was a core component of edX's governance strategy. 


\section{AllDone}

AllDone's primary challenge in governing its users was managing their responses to continual changes in the software and business model. When the first author began his research at AllDone, the company had just raised its first round of venture capital funding. Within months, executives had already set their sights on securing a second investment. As Peter, AllDone's CEO, explained at an all-staff meeting, "With Series A [funding rounds], you're selling a dream [to investors]. With Series B, you're selling a spreadsheet," or a viable business model. This meant that AllDone's small team of software engineers (which grew from 4 to 8 during the course of fieldwork) were primarily focused on developing new projects with the potential to "move the needle" on key metrics such as user growth and revenue to make the company more attractive to potential venture capital investors.

AllDone's engineers were thus subjecting the platform to constant experimentation, with its policies and user interface undergoing continual revision. Given the pressure that AllDone's developers faced in achieving substantial growth with limited resources at their disposal, soliciting input from users was not a priority for the engineering team. Instead, engineers focused on rapidly devising and testing experimental product features. Developers' primary source of insight into user preferences was behavioral data in the form of clicks that were gleaned from "A/B tests" of new features (Reis 2011). Although there were some ad-hoc exceptions to this tendency, AllDone's software developers established no formal procedures through which they systematically solicited the input of members of the user population. ${ }^{11}$

\footnotetext{
${ }^{11}$ Managers would sporadically ask email support agents to tally incoming messages pertaining to particular product features, though in practice execution could be haphazard; product designers would occasionally recruit a handful of user testers to gather feedback on potential features and to learn more about how people navigated the website; and AllDone's marketing team periodically invited small groups of local sellers to the office for lunch or happy hour, which provided occasions in which to learn from sellers about their experiences with AllDone's platform.
} 
Convincing confused, frustrated, or dissatisfied users not to exit the platform in response to its fast-changing features and policies was thus one of AllDone's most pressing tasks. Because of the scarcity of engineering resources, AllDone's management was inclined to address user discontent not through user-centered product design, but rather by, as one manager put it, "throw[ing] bodies at the problem." These "bodies" were frontline workers who provided email and phone support to AllDone users.

AllDone deployed customer support agents to engage in interpersonal interactions aimed at managing conflict, bringing users into alignment with the company's policies, and sustaining their attachment to the platform. This relationship labor was displaced onto members of AllDone's remote, work-from-home teams in the Philippines and the Las Vegas area, a substantial majority of whom were women. AllDone's relationship workers were long-term contractors who had minimal input into the company's software and policies. The 20 email support agents in the Philippines and 10 phone support agents in the Las Vegas area received far lower wages in comparison with the generously compensated staff in the San Francisco office (an average of \$2 an hour in the Philippines and \$10 an hour in Las Vegas) and no employment benefits.

In its communications with sellers, AllDone propagated the notion of a mutually beneficial, transactional relationship between the platform and its sellers. This strategy is exemplified in a short video that AllDone created to welcome new sellers to the platform. The video features an employee named Brandon speaking directly into the camera from one of the conference rooms in AllDone's San Francisco office. "AllDone's in the business of bringing you more business," he intones. As images of AllDone blog posts containing user testimonials scroll across the screen, Brandon explains that "It makes us feel good when our sellers succeed. 'Cause 
the truth is, we only succeed when our sellers do. When it comes down to it, it's a partnership." Here Brandon implicitly acknowledges that that AllDone relies on maintaining a consistent revenue stream from satisfied sellers. By claiming that "we only succeed when our sellers do," Brandon attempts to rhetorically align the financial interests of sellers with those of AllDone, obscuring any tradeoffs between an individual user's interests and AllDone's gain.

Because the company engaged in little proactive outreach to its users, AllDone's relationship workers typically interacted with users after they had already encountered some sort of problem with the platform. Some of the issues faced by users pertained to matters of education: for example, sellers who had difficulty understanding the platform's rules or its user interface required assistance in better understanding how AllDone's systems worked. Some users also found that their experiences with the platform did not conform to their expectations. Users who reached out to the company with complaints or grievances could connect with agents who would endeavor to repair the user's trust in the platform. In the following sections, we detail the relationship labor enacted by the email and phone support teams, beginning with account management practices and followed by community management practices.

\section{$\underline{\text { Account Management Practices }}$}

AllDone's relationship workers primarily engaged in account management practices aimed at aiding users and persuading those who were dissatisfied to continue to use the platform. These practices could be highly routinized, as in the case of email support agents who drew on templated responses to user queries, or highly individualized, as in the case of phone support agents who often spent long periods of time speaking with users to address their concerns. 
Many users who were upset or confused by AllDone's ever-shifting product features or policies would contact representatives of the company via email. AllDone's team of 20 email support agents worked from their homes across the Philippines. The email team was designed to respond to a high volume of incoming messages: team members would often process over 10,000 per week, and over $70 \%$ of user email messages received a response in fewer than two hours.

These speedy response times were enabled by the highly routinized nature of AllDone's email support system. Because AllDone Philippines agents' English skills could fall short of American managers' and customers' expectations, and because of the difficulty of disseminating the details of frequent, often complex product changes to remote team members, managers in San Francisco developed dozens of pre-written email responses that members of the email support team could select and send to users based on the content of a user's inquiry. The email support team was thus designed not to engage users in detailed exchanges, but rather to provide them with prompt answers to basic queries. This was not always effective, with some users replying to canned responses in frustration with messages such as, "Your response sounds robotic, so I guess your [sic] not a real person, however, I am. I have a real situation and it seems to be taken too lightly, so I have canceled my account." Agents could "escalate" unusual questions and requests or difficult responses to managers in the Philippines and ultimately to the San Francisco office.

AllDone also used email to provide disappointed buyers with more personalized attention. The company deployed another set of team members in the Philippines to alleviate buyer discontent. According to AllDone's buyer satisfaction surveys, 75 percent of dissatisfied respondents identified having received one or zero quotes from sellers as their chief source of 
frustration. When buyer requests did not obtain any quotes after 48 hours, a group of workers attempted to preempt buyer complaints about poor introductions by sending them an email apologizing for the issue. The message would add, "I wanted to go the extra mile and do a little bit of personal research to find some people who might be able to do your job," and the team member would then include a handpicked list of AllDone sellers who the buyer could contact independently if desired. A team of 12 could send over 20,000 such emails per month. AllDone thus mobilized its team in the Philippines to deliver personalized attention to buyers in an effort to repair trust in the platform, helping to preserve AllDone's reputation when it failed to furnish high-quality connections.

Buyers and sellers who were motivated and able to locate the company's customer support telephone number could call and speak directly to a customer support specialist. ${ }^{12}$ AllDone's team of ten phone support agents working from their homes in the Las Vegas area would assist users with problems and, in the event that they were upset, endeavor to regain their trust after their expectations had not been met.

I observed the following exchange between Carol, AllDone Las Vegas' team leader, and Nancy, the "account specialist" tasked with handling inquiries from AllDone's most valuable users.

"I have a ticket I want to run past you," Nancy says, referring to a customer support request logged in AllDone's system, "from Phil, a troublemaker in Miami, shocker. He's having a hissy fit." Phil is a seller who's upset that he has not been winning jobs and wants to have all of his past payments refunded.

Carol asks for the ticket number, and takes a moment to pull up Phil's file on her computer. Nancy fills the silence, adding, "I know what I would do, but I want an opinion."

\footnotetext{
${ }^{12}$ The distribution of AllDone's phone number was intentionally limited due to the relatively small number of phone support agents on staff. Some phone calls were answered when they were received, but callers would frequently be prompted to leave a voicemail message and would later have their call returned by an AllDone support agent.
} 
"Let's look at his quotes, the correspondence between them," Carol says, skimming the file. "Is he doing what he should do [personalizing his messages to buyers], or just sending a generic message?"

"Honestly, I think [his correspondence] was good," Nancy replies.

"Give him one month [of refunds]."

A pause.

"The screaming got real loud," adds Nancy.

"You can win him around, honey," Carol says cheerily. "You can Nancy him!"

Nancy's task was to convince Phil that the company had acted fairly in its dealings with him, and that it was in his interest to continue to use AllDone's services. Team members would patiently listen to a seller's concerns and offer reassurance and tips to help the seller succeed in the future. ("You can Nancy him!")

In addition to granting refunds to sellers who team members deemed worthy of material concessions, support agents most frequently used a combination of three tactics to keep users engaged with the platform. First, agents would attempt to convince frustrated sellers that their expectations of AllDone's service were unrealistic. "You have got to give them a wake-up call," Nancy explained during a videoconference in which she recounted a recent conversation with a contractor who was upset that AllDone buyers were not hiring him after he had provided inhome estimates. "'I understand [your frustration]--but how's your business outside of AllDone? Do you usually get every job you go on? 'No, I don't.' 'Well, this is the same thing.' [...] They need to hear this." Such statements were aimed at persuading users not to hold AllDone responsible for their own unsuccessful outcomes. A second, related tactic involved providing sellers with education and counseling on how to achieve better outcomes in the future. Phone support agents would review a seller's account and offer customized advice. One agent named Casey reported repeatedly telling sellers that "you need to work on your profile" by adding a 
high-quality photograph and eliminating grammatical and spelling errors. Nancy helped sellers learn how to write more personalized quotes to potential buyers. "You have to show them how to stand out from the rest," she explained, "how to answer in a nice way so [buyers] want to respond." Third, agents provided personalized attention to confused or upset users. It was common for conversations to last between 15 and 45 minutes; as team leader Carol put it, "We do therapy, as well $[\ldots]$ we give them love, and whatever they need." Extended contact with disgruntled users was aimed at making sellers feel that the company was not a faceless platform dedicated only to taking their money, but instead that AllDone cared about them and their businesses.

Tradeoffs between the interests of the users and the company became most salient when AllDone experimented with changes to its product. If the company framed its relationship with users as transactional, conflict emerged over the terms of those transactions. In these instances, AllDone's relationship workers aimed to persuade users of the fundamental fairness of the platform's policies while also making them feel that their grievances were being heard and understood. Account management was generally structured to be reactive, with relationship workers responding to user problems as they arose. In one prominent case, however, AllDone's phone support agents proactively reached out to users about a forthcoming product change. Without consulting its sellers, AllDone's management had decided to transition to a new pricing model which would increase the fees paid by the company's most active sellers by as much as 1,000 percent. Management therefore directed phone support agents to call thousands of highvalue sellers, inform them of the change, and try to convince them to try the new system in spite of their inevitable dissatisfaction with the price increase. Soon after the project began, Carol explained in an email to managers in San Francisco that "[w]e've managed to get most of [the 
sellers] to come around and agree to try the [new system], but some of these calls are taking a lot of time and a lot of tap dancing, with jazz hands, of course!" Team members absorbed weeks of abuse from angry sellers, and each was brought to tears at some point during the transition. Ultimately, their efforts were successful - enough sellers continued to use the service that AllDone's revenue continued to climb, enabling the company to attract a second round of venture capital funding.

Even when support agents' relationship labor was proactive rather than reactive, its primary function was not to solicit input from AllDone's user community to inform the design of features that would more closely reflect user preferences. These interpersonal interactions were instead intended to support the introduction of a payment model devised in a "top-down" fashion by developers in the San Francisco office who were motivated primarily by the imperative to increase short-term revenue.

\section{$\underline{\text { Community Management Practices }}$}

AllDone's messaging to sellers emphasized how the platform could help them achieve their individual goals. In the video for new sellers detailed above, the only mention of a seller's membership in a broader collective comes when Brandon states, "You've joined a large and growing community of sellers. Today, over 250,000 sellers from across the country are using AllDone to grow their business." However, there is no mention of how these quarter-million sellers might contribute to a mission greater than the growth of their individual enterprises.

Managers did, however, experiment with practices of community management by creating an online forum where some sellers could share information with one another. During one meeting, AllDone's president tasked AllDone's San Francisco team with designing a project 
that would "[make] our highest value sellers more loyal...[e]ducate sellers about AllDone...[and] [f]oster [a] sense of AllDone community." Brandon, a member of the marketing team, led an initiative for which he identified 1,000 of AllDone's most active and highest rated sellers and invited them to join a program called "AllDone Select." Those who joined the program were offered a variety of perks, including a badge on their AllDone profile pages, "VIP customer support," and access to a members-only Facebook group "where you can learn insider info from AllDone and other Select sellers." The Select Facebook group was the first forum maintained by AllDone in which users could interact with one another outside of a buyer-seller transaction. In a post on the Facebook group's page, Brandon explained that "this forum is a place where you can ask questions related to your business and AllDone, share tips, and network," indicating that this would be a space in which sellers would come together around common interests.

Sellers did occasionally use the Facebook group to share best practices and connect with other businesses in their area: for example, one photographer asked for advice from others on purchasing a new flash for a camera; a magician said he was looking to "network with" other event service providers in the Boston area; and sellers occasionally posted messages explaining that they wished to compare their service pricing with the prices charged by others who worked in their field.

However, the majority of messages were complaints about sellers' experiences with the platform--some relating to individual sellers' particular issues and some pertaining to issues that affected many sellers--directed at AllDone management. (e.g. "Hey AD Engineers (do you even read these?)"; "I've been trying to contact customer service...") These included gripes about inappropriate buyer requests ("How does this request get by? It clearly states the buyer is turning 13. Legally I couldn't have them sign a contract."), buyers with low intent to hire ("I feel like 
I'm spending nearly $\$ 15$ a pop to give advice to people who are just kicking the tires"), issues with product changes ("I also don't like the change they made to the 'dashboard."'), product features ("When we decline a request, we are asked why. WHY does the potential buyer not have to do the same [when declining a seller quote] and why can't we get feedback on why we aren't being hired?"), and policies ("I'm so upset! I just lost [money] for nothing"; "I think AD should give us [a refund] when the buyer cancel [sic] the request").

AllDone management repeatedly discouraged sellers from using the AllDone Select forum to register complaints or requests for customer service. Brandon frequently posted group messages and sent individual sellers direct messages reminding them that "instead of posting customer support related questions here," they should instead "please contact our customer support team. This is a space to share tips, engage and ask questions that may benefit other service professionals." In sum, although the AllDone Select program was designed to cultivate a collective identity among sellers and to help users work together to advance common goals, it largely failed in this regard; to the extent that it did succeed, its efficacy was limited because it only reached a small fraction of the user base.

$e d X$

Early in its trajectory, edX's senior management decided that, for the company to become financially sustainable, it would have to "scale up" by recruiting institutional partners who would offer an ever-expanding array of content. To achieve this goal, edX would have to provide its partner institutions with software that would allow them to produce new courses, credentials, and educational research. Partners would pay edX to use the company's software and host their courses on its portal, and some learners would pay edX to earn a certificate. 
In recruiting partner institutions and educators to its MOOC enterprise, edX promoted a reformist mission: "reinventing education." This slogan carried a double meaning: edX and its partners would not only reinvent the higher educational system by making courses available to learners outside of traditional university settings, but would also reinvent the practices traditionally associated with education and educational expertise. edX's “About” page stated:

As a global nonprofit, edX is transforming traditional education, removing the barriers of cost, location and access. Fulfilling the demand for people to learn on their own terms, edX is reimagining the possibilities of education, providing the highest-quality, stackable learning experiences including the groundbreaking MicroMasters ${ }^{\circledR}$ programs.

Partners had a key role to play in this mission: instructional teams and researchers at partner institutions could devise novel methods of teaching and learning that edX's management had yet to imagine. Together, edX and its users would constitute a community in pursuit of a shared goal.

edX's two institutional prerogatives--its pursuit of the organization's financial sustainability and its broader social agenda of reforming education--set up management's central challenge. The company had to encourage instructors and researchers at edX's partner institutions to generate innovative courses and research, while also ensuring that edX itself maintained control over the terms of the reform agenda and broke even financially. The company had to negotiate multiple conflicts within the ecosystem: What happens when partners have divergent demands or conflicting ideas of what counts as "reinventing education"? What happens when partners disagree with edX's decisions? What happens when the pursuit of reform clashes with edX's financial imperatives? As Beth Porter, edX's first head of Product recounted, edX's primary challenge was to balance its vision for "innovation in education" with market considerations:

[W] here we have most tensions actually, is that there [are] these two parts of our mission, one of them is really mission-driven, right, innovation in education, trying to really chart a new path, trying to lead our partners, into different and interesting forms of [...] deliver[ing] content, 
reach[ing] broader audiences, find[ing] a new revenue stream, there's all of that, and there's really just pure $[\ldots]$ commerce, $[\ldots]$ becoming a consumer product. And that, I think, is probably where more tension exists in our ecosystem than anyplace else.

While these conflicts were debated in boardrooms and high-level meetings, in the context of the day-to-day work of edX and its partners, they often came down to the characteristics of the particular software features that the edX organization prioritized. To scale up the number of its partners, edX had settled on a division of labor whereby the company would produce software that educators at partner institutions would use to "author" courses and conduct research (identifying reference). As an edX engineer put it, "We do software so that you can do education" (Huger 2014). The question of which software features to prioritize and how exactly the software features would work was often a bone of contention through which larger questions about the direction of reform were indexed.

To solicit participation beyond its paying partners, and to give its partners more choices, edX also released the source-code of its software in June 2013. This served two purposes. First, when edX partners wanted a feature that edX could not provide for them, they could write it for themselves and then contribute it back to the larger code-base, provided that they had the resources (people, time, and money) to do so. Second, a larger technical community of coders interested in building educational software could now create new features for the edX software or improve existing ones. In theory, the open-source community could step in to do things that edX and its partners could not do by themselves.

The central challenge of balancing the company's financial sustainability with the pursuit of reform was a key driver of edX's organizational structure. The engineering team designed and built the edX software; four engineers also interfaced with edX's broader open-source community. Most members of the engineering team were men, though there were women in key 
positions as well. The services team managed edX's relationships with its partners: they talked to the instructors and researchers at partner institutions and tried to help them through their difficulties with the platform. Their task was twofold: to manage partners so that they would continue to use edX in spite of the inevitable setbacks, and to communicate partners' concerns and issues to colleagues at edX. ${ }^{13}$ The services team performed the relationship labor that is the topic of this article. Unlike the engineering team, at least half of the services team were women.

Most members of the engineering and services teams worked in the edX office and shared meetings, lunches, and drinks after work. They were all relatively high-status workers who received competitive salaries and employment benefits. The services team at edX--its relationship workers--operated under titles like program manager, partner manager, or relationship manager. Relationship workers often came from business or consulting backgrounds, though they were typically expected to have some prior experience working with university faculty and administrators.

edX's relationship workers comprised the services team and the four members of the engineering team who interfaced with the open-source community. These workers employed two types of practices to manage their users (the educators at edX partners, and the open-source community of developers, respectively). Account management practices were designed to help users deal with routine issues and inquiries as they attempted to build courses or utilize the resources edX provided. Community management practices were designed to connect users to each other to encourage collaborations that could benefit both themselves and edX.

\footnotetext{
${ }^{13}$ In 2014, edX created a product team, which took charge of the company's institutional and engineering agenda (e.g. the features edX should be building or improving). Its roadmaps were based on input from members of the services team (who provided insight about users), the engineering team (who could speak to the software), and senior management (who were responsible for ensuring the company's financial security).
} 


\section{$\underline{\text { Account Management Practices }}$}

edX's relationship workers used account management practices to guide users through the everyday processes of building and executing courses and research. Although most account management activities addressed routine issues, users could also make demands that stretched or pushed against the limits of what relationship workers could do for users. Even in these instances, relationship workers strove to make users feel that they had a voice, and attempted to channel this voice back into the edX organization.

Within the edX ecosystem, course production and execution were typically the responsibility of the course teams at partner institutions. edX program managers (PMs) advised partner institutions on how to build a course team and provided step-by-step instructions for how to develop a course on the platform. edX provided extensive infrastructure to support PMs in these duties, including documentation on how to use the software, advice on best practices, checklists, project management tools, and roadmaps. PMs would also occasionally conduct inperson meetings with local instructional teams or conference calls with teams from more distant institutions.

When course teams ran into difficulties, edX PMs increased their engagement. In some cases, PMs would point teams toward appropriate resources; in others, they would take the team's concerns directly to edX's product or engineering teams. As Emily, an edX PM, put it, if "it's really urgent or something's broken," then "the PMs can kind of be an advocate for escalating something." Another PM, Rebecca, reported that program managers "have probably the most up-to-date intelligence on the [partners] at a kind of functional-operational level than the senior leaders just by the virtue of that job," and were therefore best suited to the task of brokering information between edX's users and architects. 
Emily recounted how throughout the summer she had advocated for the edX product and engineering teams to prioritize and develop one particular feature because there were several course teams that would be ready to use it during the following semester.

And so, you know, we just had something where we had a feature but it was lacking one thing, that one key thing was like a barrier to adoption. And so [...] I kind of went to the product team to say, is there any way like, is this, what's the scope of this? And if it's small, is there any way we can squeeze it into the existing sprints this summer? Because if we do a lot of courses, we'll use it in the fall (emphasis added). [...] We've done all of this work and [if it isn't completed soon] no one's going to adopt it until January.

As a result of her advocacy, the engineering team completed the feature over the summer. Emily was able to follow the progress of their work and intervene appropriately to support her course teams.

And so they actually did [it] and they created [a] story [this is how features are documented in edX's internal system]. And I was added as a follower and then they would update me like: "here's where we are"; "here's a bug that we've discovered"; "we're almost there"; "we're almost there and it emerges this week."

PMs' ability to manage users was facilitated by their capacity to directly interface with and influence edX's internal development teams. Emily identified differences between her job at edX and previous roles in the publishing industry, where editors and developers were located in “different building[s] in [...] different cit[ies]." In contrast, at edX, "if something is urgent, I can walk 10 feet away and find the person who will help me fix it. So it's very integrated."

More often than not, however, PMs were unable to persuade developers to immediately build or fix the features their instructors requested, leaving PMs with few options other than to advise course teams to temper their expectations and adjust their courses to accommodate the limitations of the software. As Emily told me, building new features was a "capacity" problem for edX. When partners requested a feature, she would often point them to edX's developmental 
"roadmap" to indicate that the team was aware of their needs and that the feature would eventually be available.

The "roadmap" was a key informational resource within the edX ecosystem that PMs used to bridge the interests of edX and its partners. PMs aggregated what they knew of their partners' needs and requests and forwarded them to the edX product team, which used this list to inform decisions about what software features the edX engineering team should work on. Every quarter, edX would publish a roadmap of upcoming features and their progress toward completion. By soliciting input and making its roadmap public, edX hoped to offer partner educators a voice in the platform's development. However, if a PM was unable to get an item added to the roadmap, then, as Emily put it, "the onus is on [partners] to develop it and contribute to it if they want it sooner."

Instructors were not always satisfied with the roadmap. Some argued that the document was too vague to be of use to them because it did not detail exactly what a feature would do and when exactly it would be available. A Harvard instructor spoke to this common concern:

Instructor: I miss the days [when edX only had two or three partners] when there was a better list of upcoming features and what stage they were in. Um, I can find that sort of thing sometimes by looking through JIRA, which is their bug-tracking and issue-tracking thing. But God, that's a slog, trying to find anything. It's impossible.

[Second Author]: How about their roadmap? Does that not help you?

Instructor: It doesn't help. It's not very specific. It doesn't tell me anything about the features. You know, if I'm going to be planning for a feature so that I can have my course designed to use something, I need [to know] months in advance, I need to know specifics. I need to know details. I can't just be told, "oh yeah, we're working on badging." Great. What can I do with it? You might as well tell me that you're going to hand out a little plastic stamp that I'm going to stamp people's paper with it. I know nothing about it. So that's, that's my big complaint, that is not having detailed information because I need it in advance if I'm going to take advantage of it. Otherwise it's going to be a year [for me to use a feature] (emphasis added).

[Second Author]: Why is it so difficult to be told in advance?

Instructor: My guess is it's just because things may change and they don't want to hear, you know, "you guys promised us this and didn't deliver this," which happened with the A/B testing. 
Um, there were features of A/B testing that didn't go out. So, you know, I can understand not wanting to hear that. On the other end, if they want to see these new features used, we need to know more about them.

The instructor's complaint highlights that although edX's information infrastructure (e.g. documentation, roadmap, templates for course production) is undoubtedly useful to its partners, these resources may not always be as transparent or useful as edX PMs make them out to be. While a roadmap does give an instructor some idea of edX's priorities, and the inclusion of a feature into the roadmap does validate the partner who is advocating for it, to fully use the roadmap as intended requires an instructor to maintain ongoing relationships with PMs. It was only by picking up the phone and asking a PM for updates or information from the engineering team that an instructor could learn exactly when a feature on the roadmap would be active and exactly what it would do.

In sum, edX's account management practices were designed to guide course teams at partner institutions through the day-to-day work of building and executing courses. Through these practices, edX PMs helped to integrate the voices of educators at partner institutions into the plans devised by the edX Product team. Account management practices were aimed at addressing users' concerns and maintaining their engagement with the platform in spite of inevitable difficulties and disappointments.

\section{Community Management Practices}

edX PMs and other relationship workers used community management practices to connect users to each other and foster communication and collaboration between partners. In doing so, community management practices could set into motion processes that forced the organization to re-evaluate its governance strategy. 
Managers at edX believed that they could enhance the value of the platform by building a sense of community among partners. edX PMs and engineers accordingly created a variety of spaces in which members of the edX ecosystem could communicate with each other, under the auspices of the edX organization itself. These included online spaces like the freewheeling edxcode mailing list (open to anyone who wanted to join, though messages were moderated); edX's partner portal, where edX released updates for its partners and hosted online forums; conferences and meetups, particularly the edX Global Forum and the Open edX Con for educators and developers interested in contributing to the edX project. The relationship labor of community management consisted of connecting partners to each other and working with them to further their goals while simultaneously steering them in a direction beneficial to edX itself. As edX program manager Emily put it:

Sometimes our job is really facilitating connections [and] leveraging partnership opportunities, even if it's just between edX and a partner or if it's between other partners who have the potential to collaborate and be stronger together than they could be [alone].

PMs used their comprehensive knowledge of the edX ecosystem to connect educators and partners to each other. Emily recalled an instance in which she had successfully brought partners together to enhance their experiences on the platform while improving the platform itself more broadly. She described a partner that wanted to "upload more than images in the peer grading," something that edX developers were not able to do for them in the near future. She discovered that there was another edX partner that had been working on something similar, but that they had stopped "for probably resources allocation reasons." She told the current partner that they were "free to pick it up $[\ldots]$ because they really wanted that feature." This partner told her that they were unsure if they could do so "because you know, that means they have to allocate resources for building it." Then a third partner emerged that also wanted the same feature for their 
upcoming course, and expressed interest in taking over development of the feature. In light of this information, the second partner volunteered to beta-test the feature in their course if somebody else would develop it. Emily then "facilitated a three-way call with the edX engineers, the original team that had started the work that had to stop, and the partner that has been currently working on the feature." The third partner decided that "we'll take it on, we want it, we will finish the work that has started." Emily had brought three partners together to build a feature that would not only enhance their courses, but would be of use to partners across the edX ecosystem.

In addition to connecting partners to each other based on their collective knowledge of activity in the ecosystem, PMs also united different people within a partner institution. At an Open edX meetup organized in edX's Cambridge office in 2016, Director of Academics and Research Nina Huntemann described how when she visited partners, she tried to get instructors and researchers from the partner institution into the same room to make them aware of each other.

We have some partners [...] who have a wonderful relationship between their research team and their instructional design teams. [But] it can be difficult for some partner universities if they don't have really good research teams and tools. That's something we would want to encourage, is going onto a campus and sort of seeing what kind of communication flow they have. Trying to present them with some structures they might set up. Sometimes it's even just saying, "hey, edX is coming, we want [you to be] in the room to see researchers and instructors." I did this at a university recently. And the course teams were like, "I didn't know there was research happening at our campus with our course data!" Yeah, so whatever we can do to facilitate that.

If PMs helped to connect educators within and across edX partner institutions to build a user community, users could also organize to force edX to reconsider its own policies and processes. This is best illustrated in an episode involving edX's open-source community. When edX released its source-code in an attempt to harness the energies of a wider community of developers, these outside developers responded by asserting that simply releasing code was not 
enough, and that the edX team had to change its procedures around accepting open-source contributions.

According to one Stanford developer, in the early days of the open-sourcing of the code, "the processes for reviewing pull requests [the terminology for a contribution to the source code] from the community seemed a little bit haphazard."

Someone would try to contribute something and it took forever to get [code] reviews [from edX], and then it seemed like they'd get one review that'll change it to be this other way, and someone else would say, "Oh, no, change it to something else." It felt almost like the people, the engineers at edX who are reviewing open-source contributions, were rewarded for saying, "No, we can't have that," but weren't rewarded for encouraging contributions.

In light of the disquiet in the open-source development community, Stanford commissioned an Open edX developer, Nate Aune, to write a report that it would then forward to edX management. ${ }^{14}$ The report would chronicle the troubles the open-source community was experiencing and make suggestions for remedying them.

The report, "Making Open edX a Thriving Open Source Project," was released publicly a year after the release of the edX source code. It argued that unless edX was able to accommodate the vision of its external developers, the Open edX project would not be truly collaborative. The report outlined a series of measures that edX should take. These included both technical changes (e.g. publishing better documentation) and an increased focus on relationship building (e.g. creating a new community manager position for the open-source community, and generating online and offline forums to better engage developers).

edX management responded to the report by, in the words of the company's community coordinator for Open edX, "working on a governance policy...[that] will include ways governance could potentially be expanded to include greater community involvement." edX

\footnotetext{
${ }^{14}$ Aune had previously worked at edX as a contractor, so he was familiar with both edX's open-source developers and the company's employees.
} 
improved its roadmap and made it more specific. It created an open-source community management team consisting of four edX engineers, all of whom had experience working for open-source projects. Additionally, edX launched the annual Open edX conference to facilitate connections among members of the open-source community. But in their response, edX management also made it clear that the developers must take responsibility for fulfilling certain obligations, such as committing people and funds to particular projects. They explicitly stated that " $[\mathrm{u}]$ ltimately, edX owns the prioritization and development of features on its roadmap, those that its own engineers develop; but, we recognize the value of community feedback and want to create a fruitful means of collecting it."

edX relationship workers used community management practices to connect their users to each other in the hope that these users would undertake mutually beneficial projects that the platform company itself lacked the resources to take on. This relationship labor fostered an organized community of users. The user community could also organize to make demands on the platform company itself, which the company was then forced to address by revising its governance procedures.

\section{Discussion: Platform Governance and Relationship Labor}

Platform governance, or how platform companies control their users, has recently risen to prominence in both scholarly and public debates. In comparing ethnographic data gathered inside two platform companies, this article makes two contributions to existing research.

First, theories of platform governance largely present governance as impersonal and procedural, a product of a platform's rules and technological systems. Although these components of governance were present in the cases of edX and AllDone, existing approaches 
obscure additional practices and processes associated with governance insofar as they do not account for the relationship labor that each enterprise deployed to manage the interface between the platform and its publics. The nature of relationship labor--taking the form of both account management and community management practices--is strikingly similar within two platforms that vary substantially across multiple dimensions. This suggests that platform companies' use of relationship labor is likely to be relatively widespread.

Second, by describing divergent strategies of platform governance employed by AllDone and edX--one of which relies almost exclusively on account management, and the other of which is supplemented by robust community management practices--we have demonstrated that patterns of relationship labor's use can vary across platforms, as can relationship workers' incorporation into organizational processes. The findings are summarized in Table 2 and detailed below.

\begin{tabular}{|c|c|c|}
\hline & AllDone & edX \\
\hline Strategy & Transactional & Collaborative \\
\hline $\begin{array}{l}\text { Account Management } \\
\text { Practices } \\
\text { Addressing users' particular } \\
\text { problems and concerns }\end{array}$ & 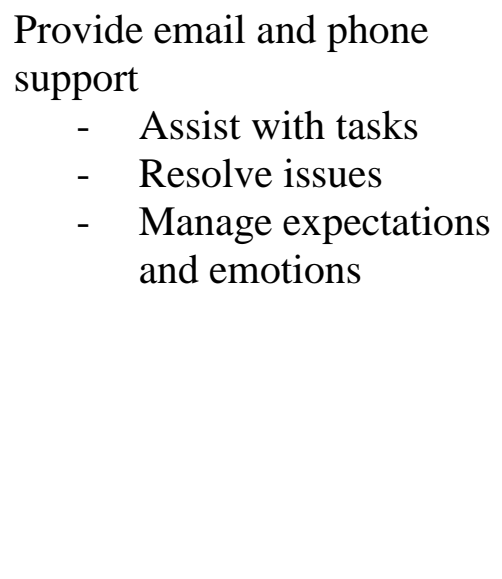 & $\begin{array}{l}\text { Provide email and phone } \\
\text { support } \\
-\quad \text { Assist with tasks } \\
-\quad \text { Resolve issues } \\
-\quad \text { Manage expectations } \\
\text { and emotions } \\
\\
\text { Create, maintain, and share } \\
\text { information infrastructure } \\
-\quad \text { Documentation } \\
-\quad \text { Templates } \\
-\quad \text { Roadmaps }\end{array}$ \\
\hline
\end{tabular}




\begin{tabular}{|l|c|c|}
\hline $\begin{array}{l}\text { Community Management } \\
\text { Practices } \\
\begin{array}{l}\text { Supporting contact and } \\
\text { collaboration among users }\end{array}\end{array}$ & $\begin{array}{c}\text { Establish and maintain venues } \\
\text { for community building } \\
-\quad \begin{array}{l}\text { Facebook group for } \\
\text { high-value sellers }\end{array}\end{array}$ & $\begin{array}{l}\text { Establish and maintain venues } \\
\text { for community building } \\
- \text { Conferences }\end{array}$ \\
& & - User meetups \\
& & $\begin{array}{l}\text { Forums } \\
\text { Identify and facilitate } \\
\text { interpersonal connections of } \\
\text { potential value }\end{array}$ \\
\hline Relationship Workers & - Offshored & - In-house \\
& - Low-status & - High-status \\
\hline
\end{tabular}

Table 2: Relationship Labor at AllDone and edX

\section{Similarities and Differences}

In this section, we leverage the comparative nature of our study to discuss the implications of the similarities and differences in the relationship labor found at AllDone and edX. In particular, we focus on the relative prevalence of account management versus community management practices, the underlying strategies that guide the deployment of relationship labor, and the status of relationship workers within the platform companies.

\section{$\underline{\text { Practices and Strategies of Relationship Labor }}$}

In both platforms, relationship workers dedicated substantial efforts to account management activities. Relationship workers interacted with users to assist them with their tasks on the platform, addressed their questions and concerns, and managed their expectations and emotions pertaining to outcomes with the platform. At AllDone, account management was largely reactive: it was users who typically initiated contact with customer support agents. At edX, course teams contacted relationship workers to seek assistance with problems, but workers also provided course teams with templates to aid them in course production and occasionally 
checked in on their progress. Relationship workers at edX supplemented these activities with community management practices designed to connect users with one another; these activities were largely absent at AllDone.

The relative distribution of account management and community management practices across edX and AllDone suggest that platform companies develop different strategies for structuring user participation and deploying relationship labor to manage it. In both cases, the practices of relationship labor were designed to prevent user "exit." However, each had a different approach to user "voice" (Hirschman 1972).

AllDone framed its platform as a source of monetary gain for sellers. Its use of relationship labor was largely transactional, aimed at solving users' individualized problems or managing users' emotions when they felt that the terms of their exchanges had been unfair. AllDone thus figured its users as individuals who would pursue their own goals in relative isolation from one another, constituting what we call a "disorganized public.” Users were afforded few opportunities to work together, organize, or articulate collective demands. Management instead inferred user preferences from their aggregated "clicks," or metrics tracking user behavior (Christin 2018). When AllDone experimented with providing an online forum for conversation among sellers, many used the forum as an alternative customer support channel in which to seek redress for their own particular issues with the platform, undermining the intended purpose of the forum.

edX, on the other hand, framed its platform as the facilitator of a social movement to reform education and positioned educators at partner institutions as potential reformers, while underplaying the financial stakes of being in the MOOC business. Relationship labor was relatively more collaborative than at AllDone. Users had more input into decisions pertaining to 
how the platform should be structured. The company also provided self-motivated users with more opportunities to come together as an "organized public" (Fish et al. 2011) in pursuit of a common mission. edX's strategy assumed the legitimacy of user voice, which edX management sought to--but could not fully--channel and contain.

\section{The Status of Relationship Workers}

These divergent approaches to channeling user voice and preventing user exit were mirrored in how managers valued relationship labor, and, by extension, relationship workers. In both companies, relationship labor was key to the platform's success. Yet at AllDone, relationship labor was considered low-status and performed by offshored contractors, out of sight of the engineers and designers responsible for building the platform. At edX, relationship labor was relatively high-status and located in the organization's headquarters, allowing relationship workers to share their frontline knowledge of user difficulties and concerns with the software development team. edX's relationship workers received competitive salaries and employment benefits, whereas AllDone's Las Vegas-based support agents were paid \$10 per hour with no benefits, and Filipino workers typically earned around $\$ 2$ per hour.

At both companies, women were more likely to perform relationship labor than engineering work. At least half of edX's Program Managers were women, in contrast to the company's more male-dominated Engineering team. Members of AllDone's Las Vegas-based team were all women, as were at least two-thirds of its Filipino workforce, while its technical workforce was almost exclusively male. These findings are consistent with previous research on occupational segregation in the tech industry. Whereas men hold the vast majority of prestigious and highly remunerative technical jobs (Harrison 2019), women tend to work in marketing, 
public relations, and roles that involve "enabling" or "co-ordinating" the activities of others, which typically pay less than technical work (Hesmondhalgh and Baker 2015). Although the status of relationship labor differed across the two platforms, the most highly valued roles in both firms were dominated by men.

\section{Boundary Conditions Affecting the Nature of Relationship Labor}

In developing an explanation of how platforms use relationship labor, we described the common and divergent practices for managing users across both of our settings. Each platform's use of relationship labor varied with three contrasting sets of organizational conditions: the platform's mission, the types of users each platform catered to, and the resources available to manage users.

\section{$\underline{\text { Mission and Goal }}$}

Arguably the most important difference between AllDone and edX was how each company framed its mission to external and internal stakeholders. AllDone told sellers that it could help them grow their businesses while saving buyers time and money by helping them connect with the right service providers. Internally, AllDone concentrated on pleasing its venture capital investors by rapidly and dramatically increasing the value of the company. edX had to establish its financial sustainability, but it was a non-profit enterprise that framed its mission as sparking and supporting a social movement, and the company configured its users as reformers who wanted to "reinvent education." AllDone's users expected to receive high-quality introductions to buyers or sellers of services, whereas edX's users--particularly its instructors 
and researchers--had no expectation of financial gain, and many were highly motivated to support the cause that edX championed.

These differences had consequences for the configuration of relationship labor. As members of an ostensible social movement, edX's users were more likely to harbor the expectation that their voice would contribute to a conversation, and perhaps even to the direction of the platform. Thus it is not surprising that edX's relationship workers helped to foster collaboration among users while sometimes helping to incorporate user voice into revisions of the platform's software or procedures. AllDone's sellers, on the other hand, had joined the platform to realize monetary gain. The company's relationship labor was accordingly organized around alleviating sellers' disappointment and anger when the reality of using the platform failed to meet their expectations, and aimed at helping them achieve better market outcomes in the future.

\section{Attributes of Users}

In addition to a platform's goals and its users' interests, the attributes of users themselves may also influence how platforms structure their relationship labor. Many of edX's users were backed by powerful partner institutions that were able to bring pressure to bear on edX to advance their own interests, as well as the needs of their instructors and researchers. edX ostensibly allowed outside developers to contribute to the software, but members of the opensource community felt that their suggestions were being ignored by edX's development team. A group of developers from Stanford mobilized the university's deep pockets and institutional clout to recruit an independent developer to write a public report, channeling the voice of the open- 
source community to get edX management's attention about the dire state of its relationship with open-source developers.

When users have ties to institutional sources of power, relationship workers must take greater care to make them feel that their suggestions are being carried back to, and given serious consideration by, the platform's architects. The high status of edX's relationship workers within the organization reflects both the power of their clients and the necessity that they be in a position to more forcefully advocate for these users.

\section{$\underline{\text { Resources }}$}

In addition to a platform's mission and the attributes of its users, the resources available to manage those users can also shape the nature of the relationship labor it deploys. When a platform company faces greater funding constraints, it may be more likely to invest its scarce resources in technical work. Changes to a platform's software can "scale" in a way that one-toone, interpersonal communications with users cannot: by revising a feature in the code, developers can instantly affect the experience of the entire user population. When resources are more abundant, on the other hand, platforms are more likely to have the capacity to invest in relationship labor and to incorporate feedback channeled through relationship workers into technical decision-making.

When the first author began his fieldwork, AllDone had just raised $\$ 4.5$ million in venture capital funding, and during the course of his research the engineering corps grew from four to eight employees. edX, on the other hand, had received $\$ 60$ million in seed funding, and during the second author's fieldwork grew its team of software engineers from about 20 to 50 . Given this disparity, it is understandable why AllDone's management chose to invest its 
relatively limited resources in its software development team, offshoring its relationship labor and "throw[ing] bodies at the problem" of managing dissatisfied users.

\section{Conclusion}

Digital platforms are playing an increasingly important role in social domains as diverse as commerce, education, and entertainment. By moving beyond analyses of platforms' rules and technologies, this article highlights the interactive processes through which platform companies manage the participation of their users. The common practices used by relationship workers at AllDone and edX suggest that relationship labor is a significant yet overlooked component of the supposed "algorithmic management" of users, and of platform governance more broadly. Emerging research documents the presence of relationship labor on some digital labor platforms (Attwood-Charles 2019; Gerber and Krzywdzinski 2019; Rahman 2019), and recent reporting reveals that even large-scale platforms like Facebook employ relationship workers to cultivate ties with revenue-generating customers (Seetharaman 2019). To our knowledge, ours is the first study to systematically investigate what relationship workers do and how corporate strategies shape the nature of relationship labor.

Further research is needed to disentangle how the various organizational constraints that platforms face at different moments in their developmental trajectories shape their strategies for deploying relationship labor. When platforms change, they can elicit emotional responses from users, and these reactions may not be effectively managed with algorithms alone. Moreover, platform companies may not only seek to understand and manage users through the measurement of clicks and A/B testing; they also can deploy relationship workers who seek to aid and persuade users while also channeling users' voices back to the platform company. Does edX's 
competitor, Coursera--a for-profit platform with institutional users and a somewhat high-minded mission--employ similar strategies for managing users? Or consider the case of Etsy, a marketplace platform like AllDone that was founded with the idealistic goal of supporting women entrepreneurs. This mission was central to the identities of many of the platform's early employees and participants, but the company's strategic imperatives changed once it became a publicly traded company obligated to respond to the expectations of a new set of investors (Gelles 2017). How did Etsy's approach to relationship labor change with its organizational constraints? Future research may also uncover additional practices and strategies for structuring relationship labor that were not present in our case studies.

Our findings also contribute to research on the connection between software algorithms and human labor. Although tech companies frequently portray digital platforms as fully automated, impersonal, and procedural systems, the capabilities of software algorithms remain limited. Recent research has shown that many platforms employ far-flung contractors to perform routinized, information-processing tasks to train machine-learning algorithms and adjust or supplement their output (Irani 2015; Roberts 2019; Suri and Gray 2019). The relationship labor described in this study represents another type of work that is emerging in and around algorithmic systems (Kellogg, Valentine, and Christin 2020) that has thus far received far less attention. When algorithmic systems fail to meet the expectations of their designers or users, tech companies may deploy human workers possessing skills that software lacks--including creativity, situational adaptability, and persuasion--in order to smooth over the gaps, snags, and lags in algorithmic systems. Platform companies continually recalibrate their policies and technologies in response to corporate imperatives and user activity (Shestakofsky 2017). Relationship labor thus represents an occupation that is likely to grow as algorithmic systems are 
deployed more widely across the economy. This article presents new insights into the nature of this work and how it might vary across organizations and fields (Kellogg et al. 2020).

The emergence of relationship labor in digital platforms raises important questions about the quality and distribution of the work that is being created. Our comparison of relationship labor in two platforms demonstrates that there is nothing inevitable about the nature of these jobs: they may be handled by low-wage contractors working from their homes far from corporate headquarters, or they may be held by well-compensated employees who work alongside a platform's software engineers and are incorporated into an organization's software design processes. Our case studies suggest that a platform company's mission, resources, and the attributes of its users can shape how enterprises organize relationship labor. Studies of other platforms may reveal additional factors that condition the status of relationship workers.

Our findings suggest that although the rise of relationship labor in platform companies may generate new employment opportunities for women in the tech industry, it may simultaneously reinforce existing patterns of occupational segregation according to which men hold the majority of technical positions and women are more likely to take on roles involving enabling or coordinating the activities of others (Hesmondhalgh and Baker 2015). ${ }^{15}$ It may also be the case that in settings where relationship labor is more highly valued, a greater proportion of these jobs will be captured by men, as is reflected in our case studies (Carter and Carter 1981).

Given contemporary trends in platform economics, demand for relationship labor is likely to intensify in the coming years. Over the past decade, hugely popular platform companies like Uber have drawn from a seemingly bottomless well of venture capital funding (Srincek 2017).

\footnotetext{
${ }^{15}$ There is a long history of women being tasked with performing the affective work that makes capitalist exchange possible, and also of the erasure of such efforts from discussions of work (Hochschild 1983; Weeks 2007; Baym 2015).
} 
However, it appears that investors are becoming increasingly reluctant to fund unprofitable enterprises (Phillips, Grocer, and Griffith 2019). As Vallas (2019:55) notes, "[i]f investor capital loses its patience, and platforms are compelled to shift their payment models, the governance problems of many platforms are only likely to grow." In their pursuit of profits, many platform companies will face the unenviable task of convincing users to pay substantially more for services that have long been subsidized by investors. Relationship labor is likely to become an increasingly salient dimension of platform governance as companies struggle to maintain user engagement amid the transformation of their business models. Although platform companies promise to change the world by leveraging technology to more efficiently connect people with the things that they want, it is the human workers charged with filling the gaps in technological systems who may in fact represent platforms' last line of defense in a fast-changing digital landscape.

\section{References}

Agre, Philip E. 1995. "Conceptions of the User in Computer Systems Design." Pp. 67-106 in Cambridge Series on Human Computer Interaction, edited by Peter J. Thomas. New York: Cambridge University Press.

Anteby, Michel. 2013. "Relaxing the Taboo on Telling Our Own Stories: Upholding Professional Distance and Personal Involvement." Organization Science 24(4):1277-1290.

Ask, Kristine, Hendrik Storstein Spilker, and Martin Hansen. 2019. "The Politics of UserPlatform Relationships: Co-scripting Live-streaming on Twitch.tv." First Monday 24(7).

Attwood-Charles, William. 2019. "Dimensions of Platform Labor Control and the Experience of Gig Couriers." Paper presented at Fathomless Futures: Algorithmic and Imagined, New York, June 27.

Bandelj, Nina. 2012. "Relational Work and Economic Sociology." Politics \& Society 40(2):175201. 
Bandelj, Nina. 2015. "Thinking about Social Relations in Economy as Relational Work." In $R e$ Imagining Economic Sociology (Eds: Patrik Aspers and Nigel Dodd):227-251.

Baym, Nancy. 2015. "Connect With Your Audience! The Relational Labor of Connection.” The Communication Review 18(1):14-22.

Bechky, Beth and Siobhan O’Mahony. 2015. "Leveraging Comparative Field Data for Theory Generation.” Pp. 168-176 in Handbook of Qualitative Organizational Research, edited by Kimberly Elsbach and Roderick Kramer. New York: Routledge.

Bell, Stephen, Andrew Hindmoor, and Frank Mols. 2010. "Persuasion As Governance: A StateCentric Relational Perspective.” Public Administration 88(3):851-870.

Bucher, Tania. 2013. "Objects of Intense Feeling: The Case of the Twitter API : Computational Culture." Computational Culture 3. http://computationalculture.net/article/objects-of-intensefeeling-the-case-of-the-twitter-api.

Bucher, Taina. 2018. If... Then: Algorithmic Power and Politics. New York: Oxford University Press.

Bucher, Tania, and Anne Helmond. 2017. "The Affordances of Social Media Platforms." Pp. 223-253 in The SAGE Handbook of Social Media, edited by Jean Burgess, Thomas Poell, and Alice Marwick. Thousand Oaks, CA: SAGE.

Burrell, Jenna. 2016. "How the Machine 'Thinks': Understanding Opacity in Machine Learning Algorithms.” Big Data \& Society 3(1):1-12.

Callon, Michel. 1984. "Some Elements of a Sociology of Translation: Domestication of the Scallops and the Fishermen of St. Brieuc Bay." The Sociological Review 32(1):196-233.

Carter, Michael J. and Susan Boslego Carter. 1981. "Women's Recent Progress in the Professions, or, Women Get a Ticket to Ride after the Gravy Train Has Left the Station." Feminist Studies 7(3):476-504.

Cheney-Lippold, John. 2011. "A New Algorithmic Identity Soft Biopolitics and the Modulation of Control." Theory, Culture \& Society 28(6):164-81.

Christin, Angèle. 2018. "Counting Clicks: Quantification and Variation in Web Journalism in the United States and France.” American Journal of Sociology 123(5):1382-1415.

Couldry, Nick and Jose Van Dijck. 2015. "Researching Social Media as If the Social Mattered." Social Media + Society 1(2):1-7.

Crawford, Kate and Tarleton Gillespie. 2016. "What is a Flag For? Social Media Reporting Tools and the Vocabulary of Complaint." New Media \& Society 18(3):410-428. 
Coleman, Gabriella. 2013: Coding Freedom: The Ethics and Aesthetics of Hacking. Princeton, NJ: Princeton University Press.

Dror, Yuval. 2015. “'We Are Not Here for the Money': Founders' Manifestos.” New Media \& Society 17(4):540-555.

Dyché, Jill. 2001. The CRM Handbook: A Business Guide to Customer Relationship Management. Boston: Addison-Wesley Professional.

Eisenmann, Thomas R., Geoffrey Parker, and Marshall Van Alstyne. 2009. "Opening Platforms: How, When and Why?" Pp. 131-162 in Platforms, Markets and Innovation, edited by Annabelle Gawer. Northampton, MA: Edward Elgar.

Fish, Adam, Luis F.R. Murillo, Lilly Nguyen, Aaron Panofsky, and Christopher M. Kelty. 2011. "Birds of the Internet." Journal of Cultural Economy 4(2):157-87.

Fourcade, Marion, and Kieran Healy. 2016. "Seeing like a Market." Socio-Economic Review 15(1):9-29.

Gawer, Annabelle and Michael A. Cusumano. 2002. Platform Leadership: How Intel, Microsoft, and Cisco Drive Industry Innovation. Boston, MA: Harvard Business School Press.

Gebre-Medhin, Benjamin. 2018. "Reengineering Elite Universities: Massive Open Online Courses and the Rise of Applied Science in American Higher Education.” Ph.D. dissertation, Department of Sociology, University of California, Berkeley.

Geiger, R. Stuart. 2017. "Beyond Opening up the Black Box: Investigating the Role of Algorithmic Systems in Wikipedian Organizational Culture.” Big Data \& Society 4(2):1-14.

Gelles, David. 2017. "Inside the Revolution at Etsy." The New York Times. Retrieved May 12, 2020 (https://www.nytimes.com/2017/11/25/business/etsy-josh-silverman.html).

Gillespie, Tarleton. 2010. “The Politics of 'Platforms'.” New Media \& Society 12(3):347-364.

Gillespie, Tarleton. 2014. "The Relevance of Algorithms." Pp. 167-193 in Media Technologies: Essays on Communication, Materiality, and Society, edited by Tarleton Gillespie, Pablo J.

Boczkowski, and Kirsten A. Foot. Cambridge, MA: MIT Press.

Gillespie, Tarleton. 2018a. Custodians of the Internet: Platforms, Content Moderation, and the Hidden Decisions That Shape Social Media. New Haven, CT: Yale University Press.

Gillespie, Tarleton. 2018b. "The Scale Is Just Unfathomable" Logic. Retrieved September 17, 2019 (https://logicmag.io/04-the-scale-is-just-unfathomable/).

Gorwa, Robert. 2019. "What is Platform Governance?" Information, Communication \& Society 22(6):854-871. 
Gramsci, Antonio. 1992. Prison Notebooks. Vol. 2. New York: Columbia University Press.

Gray, Mary L. and Siddharth Suri. 2019. Ghost Work: How to Stop Silicon Valley from Building a New Global Underclass. Boston: Houghton Mifflin Harcourt.

Harrison, Sara. 2019. "Five Years of Tech Diversity Reports--and Little Progress." Wired. Retrieved April 20, 2020 (https://www.wired.com/story/five-years-tech-diversity-reports-littleprogress/).

Helmond, Anne. 2015. "The Platformization of the Web: Making Web Data Platform Ready." Social Media + Society 1 (2):1-11.

Hesmondhalgh, David and Sarah Baker. 2015. "Sex, Gender and Work Segregation in the Cultural Industries.” The Sociological Review 63(S1):23-36.

Hochschild, Arlie R. 1983. The Managed Heart: Commercialization of Human Feeling. Berkeley, CA: University of California Press.

Huger, Jen. 2014. “3 Million Users and Hiring at edX.” Opensource.com. September 16. https://opensource.com/education/14/9/interview-ned-batchelder-openedx.

Irani, Lilly. 2015. “The Cultural Work of Microwork.” New Media \& Society 17(5):720-739.

Jackson, Steven. 2014. "Rethinking Repair." Pp. 221-240 in Media Technologies: Essays on Communication, Materiality, and Society, edited by Tarleton Gillespie, Pablo J. Boczkowski, and Kirsten A. Foot. Cambridge, MA: MIT Press.

Kellogg, Katherine C., Melissa A. Valentine, and Angèle Christin. 2020. “Algorithms at Work: The New Contested Terrain of Control.” Academy of Management Annals 14(1):366-410.

Kelty, Christopher, Aaron Panofsky, Morgan Currie, Roderic Crooks, Seth Erickson, Patricia Garcia, Michael Wartenbe, and Stacy Wood. 2015. "Seven Dimensions of Contemporary Participation Disentangled." Journal of the Association for Information Science and Technology 66(3):474-488.

Kelkar, Shreeharsh. 2018. "Engineering a Platform: The Construction of Interfaces, Users, Organizational Roles, and the Division of Labor." New Media \& Society 20(7):2629-2646.

Kenney, Martin and John Zysman. 2016. "The Rise of the Platform Economy." Issues in Science and Technology 32(3):61-69.

Klonick, Kate. 2017. "The New Governors: The People, Rules, and Processes Governing Online Speech.” Harvard Law Review 131:1598-1670. 
Li, Tania. 2007. The Will To Improve: Governmentality, Development, and the Practice of Politics. Durham, NC: Duke University Press.

Mackay, Hugh, Chris Carne, Paul Beynon-Davies, and Doug Tudhope. 2000. "Reconfiguring the User: Using Rapid Application Development." Social Studies of Science 30(5):737-757.

Mason, Colin. 2009. "Venture Capital." Pp. 131-137 in International Encyclopedia of Human Geography, edited by Rob Kitchin and Nigel Thrift. London: Elsevier.

Matias, J. Nathan. 2016. "Going Dark: Social Factors in Collective Action Against Platform Operators in the Reddit Blackout." CHI"l6.

Nieborg, David and Thomas Poell. 2018. "The Platformization of Cultural Production:

Theorizing the Contingent Cultural Commodity.” New Media \& Society 20(11):4275-4292.

Parker, Geoffrey, Marshall W. Van Alstyne, and Sangeet Paul Choudary. 2016. Platform Revolution: How Networked Markets are Transforming the Economy and How to Make Them Work for You. WW Norton \& Company.

Phillips, Matt, Stephen Grocer, and Erin Griffith. 2019. Wall Street Deflates America's Favorite Start-Ups. The New York Times.

Plantin, Jean-Christophe, Carl Lagoze, Paul N. Edwards, and Christian Sandvig. "Infrastructure Studies Meet Platform Studies in the Age of Google and Facebook." New Media \& Society 20(1):293-310.

Postill, John. 2008. "Localizing the Internet Beyond Communities and Networks." New Media \& Society 10(3):413-431.

Puschmann, Cornelius and Jean Burgess. 2013. "The Politics of Twitter Data." http://papers.ssrn.com/sol3/papers.cfm?abstract_id=2206225.

Rahman, Hatim. 2019. "From Iron Cages to Invisible Cages: Algorithmic Evaluations in Online Labor Markets." Working Paper. Stanford University.

Roberts, Sarah T. 2019. Behind the Screen: Content Moderation in the Shadows of Social Media. New Haven, CT: Yale University Press.

Rosenau, James N. 2009. "Governance, Order, and Change in World Politics." Pp. 1-20 in Governance Without Government: Order and Change in World Politics, edited by James N. Rosenau and Ernst-Otto Czempiel. New York: Cambridge University Press.

Rosenblat, Alex. 2018. Uberland: How Algorithms Are Rewriting the Rules of Work. Oakland, CA: University of California Press. 
Rosenblat, Alex and Luke Stark. 2016. "Algorithmic Labor and Information Asymmetries: A Case Study of Uber's Drivers." International Journal of Communication 10:3758-3784.

Seaver, Nick. 2019. “Captivating Algorithms: Recommender Systems as Traps.” Journal of Material Culture 24(4):421-436.

Seering, Joseph, Tony Wang, Jina Yoon, and Geoff Kaufman. 2019. "Moderator Engagement and Community Development in the Age of Algorithms." New Media \& Society 21(7):14171443.

Seetharaman, Deepa. 2019. "How a Facebook Employee Helped Trump Win--But Switched Sides for 2020." The Wall Street Journal. Retrieved April 28, 2020 (https://www.wsj.com/articles/how-facebooks-embed-in-the-trump-campaign-helped-thepresident-win-11574521712).

Shapin, Steven. 2008. The Scientific Life: A Moral History of a Late Modern Vocation. Chicago: University of Chicago Press.

Shestakofsky, Benjamin. 2017. "Working Algorithms: Software Automation and the Future of Work." Work and Occupations 44(4):376-423.

Squirrell, Tim. 2019. "Platform Dialectics: The Relationships between Volunteer Moderators and End Users on Reddit." New Media \& Society 21(9):1910-1927.

Srnicek, Nick. 2017. Platform Capitalism. Hoboken, NJ: Wiley \& Sons.

Suzor, Nicolas. 2019. Lawless: The Secret Rules That Govern Our Digital Lives. New York: Cambridge University Press.

Tufekci, Zeynep. 2014. "Engineering the Public: Big Data, Surveillance and Computational Politics.” First Monday 19 (7). http://firstmonday.org/ojs/index.php/fm/article/view/4901.

Vallas, Steven P. 2019. "Platform Capitalism: What's At Stake For Workers?” New Labor Forum 28(1): 48-59.

Vallas, Steven and Juliet B. Schor. Forthcoming. "What Do Platforms Do? Understanding the Gig Economy.” Annual Review of Sociology 46.

Van Dijck, Jose. 2013. The Culture of Connectivity: A Critical History of Social Media. New York: Oxford University Press.

Van Dijck, José, Thomas Poell, and Martijn De Waal. 2018. The Platform Society: Public Values in a Connective World. New York: Oxford University Press.

Weeks, Kathi. 2007. "Life Within and Against Work: Affective Labor, Feminist Critique, and Post-Fordist Politics." Ephemera 7(1):233-249. 
Zelizer, Viviana. 2005. The Purchase of Intimacy. Princeton, NJ: Princeton University Press.

Zuckerberg, Mark. 2017. "Building Global Community." Facebook. Retrieved March 9, 2020 (https://www.facebook.com/notes/mark-zuckerberg/building-globalcommunity/10154544292806634/). 